\section{A historical review of head and neck cancer in celebrities}

$J$ Laryngol Otol, Published online by Cambridge University Press 2 Nov 2006

Dear Sirs

With great interest we read Folz and colleagues' article on head and neck cancer in celebrities. We can extend that splendid research with some more interesting facts.

The famous American jazz musician Dexter Keith Gordon (1923-1990) also died of laryngeal cancer (in addition to being a smoker, he was also an alcoholic and a heroin addict, and he suffered from liver cirrhosis and kidney lesions). It is supposed that the renowned Finnish composer Jan Sibelius (1865-1957) developed a deep, long-standing anxious-depressive state on account of a suspected (but never confirmed) laryngeal cancer; he died at the age of 92 of stroke. Probably the most prominent Croatian writers and poets, Antun Gustav Matos and Tin Ujevic, also died of laryngeal cancer.

However, we emphasise the pathography of the famous Austrian composer, director and singer Franz Suppé (1819-1895). He was born in Split, Croatia, and, along with the Strauss family and Millöcker, won glory in the field of Viennese operetta. His last years were disturbed by professional problems and development of pharyngeal (throat) cancer that was not adequately diagnosed early enough or treated accordingly. Serious neuralgic pains appeared, together with a change in voice and digestive disorders (causing nausea with ingestion). An advisory council, consisting of well known Viennese physicians, was formed only in Suppé's last two weeks. They recorded in their preserved two-week report that the maestro was suffering from acute, serious indigestion and gastric difficulties. This was followed by the appearance of strong nausea, accompanied by bad feeling and heavy exhaustion, with serious, painful (and sometimes bloody) vomiting. Finally, this led to an intense loss of vigour, especially of the heart, with a weak, intermittent pulse and tachycardia. Delirium then commenced. Somnolence and loss of consciousness became more frequent and more profound, and the patient died at the age of 76 . Unlike Puccini, he managed to give a well rounded quality to his creative opus.

We can also supplement interesting pathography for Giacomo Puccini. An advisory council, consisting of Torrigani, Toti and Gradenigo, was moved by Puccini's weight loss, hoarseness, neck pains, high and deep voice changes, and coughing with bloody sputum. The council ascertained a sub- (and not supra-) glottal tumour (which required an intervention of laryngeal fenestration). They sent Puccini to Brussels, where radium was applied outside and finally surgically inside. The condition responded remarkably at first. Puccini was able to walk in the hospital, he was allowed to smoke again, and a temporary discharge before the final surgical intervention was planned. The prognosis was allegedly good (it would be so, especially in today's conditions), and Puccini wrote, 'I am saved'. But 'cardiac crisis' with tachycardia and rapid loss of consciousness set in, suddenly followed by death. ${ }^{1-4}$
Articles such as Folz and colleagues' really do increase awareness of these illnesses. Such reports can have a positive effect on public health and on our present patients, who might find strength and comfort in the fact that some of the most prominent figures in present and past history have also fought the same battles.

T Breitenfeld,

D Breitenfeld,

N Jagetic*,

L Bergovec*

From the Neurology Department, Sisters of Charity University Hospital, and the ${ }^{*}$ Traffic Medicine Polyclinic, Park Polyclinic, Zagreb, Croatia.

\section{References}

1 Breitenfeld D, Breitenfeld T, Šimunić M, Blazic-Cop N, Golik-Gruber V. Pathographies of great men in history [in Croatian]. Liječničke Novine 1997;146:37-40

2 Breitenfeld D, Thaller V, Bergove M, Breitenfeld T, Prstačić M, Jagetić N. Jean Sibelius - pathography. Alcoholism 2004:2:149-51

3 Spencer FJ. Jazz and Death. Jackson: University Press of Mississippi, 2002

4 Breitenfeld V, Breitenfeld D, Breitenfeld T. The infectious fate of the Viennese Waltz originators (Lanner, Strauß, Suppé, Millöcker) [in Croatian]. Liječničke Novine 1999; 143:50-2

\section{Authors' reply}

\section{Dear Sirs}

We are most grateful for the kind recognition given to our work by Drs Breitenfeld and co-workers. It was in fact our aim to demonstrate that head and neck cancer does not only occur in socially underprivileged people. The reported cases show how celebrity patients have coped with personal health crises, in some cases even with a simultaneous professional crisis. Not everyone would be able to face so many problems and keep their spirits high. Perhaps these examples can help us in our daily routine with cancer patients. If head and neck cancer patients lose hope, they might find some consolation when they hear the stories of, for example, Ulysses Grant and Grover Cleveland.

It was very interesting to read the additional information provided by Breitenfeld and co-workers. The list of celebrity head and neck cancer patients could even be extended further. For example, the following famous actors supposedly suffered from head and neck cancer: Humphrey Bogart (oesophageal cancer); Lana Turner ("throat cancer'); Gert Fröbe (head and neck cancer); Amanda Blake (who played the part of Miss Kitty in the TV show Gunsmoke; 'throat cancer'); Graham Chapman (comedian, writer and member of the Monty Python comedy troupe; 'throat cancer'); and Lon Chaney Sr ('throat cancer').

Many other creative people, such as writers and singers and even secretaries of state, have suffered from head and neck cancer. The reason why we did not include 
more cases in our review was that there are no published medical reports on these cases, and our information would have relied on basic biographical material. Perhaps this discussion can encourage more colleagues to publish their most interesting celebrity cases (with the consent of the patients and relatives, of course). It would be especially helpful to encourage living celebrity patients to discuss their health problems freely. The lessons which we have learned from the discussion about HIV and AIDS shows that celebrities can have a tremendous impact on public health perception, and it is about time that head and neck cancer patients built their lobby.

Regarding the site of Puccini's cancer, MarcheseRagona et al. ${ }^{1}$ wrote, 'Puccini consulted Torrigiani, an otolaryngologist in Florence. He diagnosed an advanced extrinsic cancer of the supraglottis with the dimension of a walnut'.

B J Folz,

A Ferlito*,

$\mathrm{N}$ Weir $^{\dagger}$
L W Pratt ${ }^{*}$,

A Rinaldo*,

J A Werner**

From the ENT Department, Karl-Hansen Medical Center, Bad Lippspringe, Germany, the *ENT Clinic, Department of Surgical Sciences, University of Udine, Italy, the Department of Otolaryngology-Head and Neck Surgery, Royal Surrey County Hospital, Guildford, UK, the Department of Otolaryngology, Boston University School of Medicine, USA, and the ${ }^{* *}$ Department of Otorhinolaryngology-Head and Neck Surgery, Philipp University Marburg, Germany.

\section{Reference}

1 Marchese-Ragona R, Marioni G, Staffieri A. The unfinished Turandot and Puccini's laryngeal cancer. Laryngoscope 2004; 114:911-14

\section{Online Only Papers}

\section{Clinical Records}

Another reason for intra-operative imaging during cochlear implantation, M Viccaro, E De Seta, E Covelli, V Marvaso, R Filipo, E12

Rhinosporidiosis of trachea: a clinical cause for concern, $R$ Arora, $R$ Gupta, Amit Kumar Dinda, E13 